\title{
Effect of different treatments on the ability of $\alpha$-lactalbumin to form nanoparticles
}

\author{
I. J. Arroyo-Maya, ${ }^{\star}$ J. O. Rodiles-López, ${ }^{*}$ M. Cornejo-Mazón,† G. F. Gutiérrez-López, ${ }^{*}$ A. Hernández-Arana,‡ \\ C. Toledo-Núñez, ¥ G. V. Barbosa-Cánovas,§ J. O. Flores-Flores,\# and H. Hernández-Sánchez*1 \\ *Departamento de Graduados e Investigación en Alimentos, and \\ †Departamento de Biofísica, Escuela Nacional de Ciencias Biológicas, Instituto Politécnico Nacional, Carpio y Plan de Ayala, CP. 11340, \\ México, DF, México \\ ‡Departamento de Química, Universidad Autónoma Metropolitana, Unidad Iztapalapa, México, DF, México \\ §Department of Biological Systems Engineering, Washington State University, Pullman 99164-6120 \\ \#Centro de Ciencias Aplicadas y Desarrollo Tecnológico, Universidad Nacional Autónoma de México, México, DF, México
}

\begin{abstract}
Nanoparticles of bovine $\alpha$-lactalbumin $(\alpha-\mathrm{LA})$ prepared by desolvation and glutaraldehyde crosslinking are promising carriers for bioactive compounds in foods. The objective of this work was to study the effect of changes in hydrophobic interactions by using different desolvating agents (acetone, ethanol, or isopropanol) and the use of a heat or high-pressure treatment step before the desolvation process on the size, structure, and properties of $\alpha$-LA nanoparticles. In all cases, a high average particle yield of $99.63 \%$ was obtained. Smaller sizes $(152.3 \mathrm{~nm})$ can be obtained with the use of acetone as the desolvating agent and without any pretreatment. This is the first time that $\alpha$-LA nanoparticles in the size range of 100 to $200 \mathrm{~nm}$ have been obtained. These nanoparticles, with an isoelectric point of 3.61 , are very stable at $\mathrm{pH}$ values $>4.8$, based on their $\zeta$-potential, although their antioxidant activity is weak. The use of the desolvating agent with the smallest polarity index (isopropanol) produced the largest particles (293.4 to $324.9 \mathrm{~nm}$ ) in all cases. These results support the idea that controlling hydrophobic interactions is a means to control the size of $\alpha$-LA nanoparticles. No effect of pretreatment on nanoparticle size could be detected. All types of nanoparticles were easily degraded by the proteolytic enzymes assayed.
\end{abstract}

Key words: $\alpha$-lactalbumin, nanoparticle, desolvation method, high hydrostatic pressure

\section{INTRODUCTION}

Bovine $\alpha-\mathrm{LA}$ is one of the main proteins in cheese whey, making up approximately $20 \%$ of the total protein. It is thus quantitatively the second most im-

Received October 28, 2011.

Accepted July 1, 2012.

${ }^{1}$ Corresponding author: hhernan1955@yahoo.com portant protein in whey, possesses 4 intramolecular disulfide bonds without free thiol groups, and has a fundamental role in lactose biosynthesis (Farrell et al., 2004). Compared with other milk proteins, $\alpha$-LA has relatively high proportions of essential amino acids such as tryptophan, lysine, and cysteine (Kamau et al., 2010). Whey proteins are commonly used in the food industry because of their nutritive value and functional properties. The most important functional properties of whey proteins are solubility, viscosity, gel formation, emulsification, foaming, and, like many other albumins, the capacity to form nanoparticles (Mehravar et al., 2009). Nanoparticles are defined as particulate dispersions or solid particles with a diameter in the range of 10 to $1,000 \mathrm{~nm}$ (Mohanraj and Chen, 2006). Protein nanoparticles have interesting physicochemical properties such as size, surface potential, hydrophobichydrophilic balance, controlled release, and particle degradation characteristics. They are also biodegradable, nonantigenic, metabolizable, and easily modifiable for surface alteration and covalent attachment of other molecules (Jahanshahi and Babaei, 2008). The first 3 characteristics, along with the complete elimination of any residual cross-linking agent, are very important to be able to consider the protein nanoparticles as safe and effective (Wei et al., 2009). These factors and their subcellular size explain, in part, why protein nanoparticles have been recognized as potential carriers for bioactive ingredients such as peptides, vitamins, and antioxidants. In the particular case of $\alpha-L A$, this whey protein can function as a transport protein for lipophilic compounds because of their high affinity (Cawthern et al., 1997), so nanoparticles prepared with $\alpha$-LA could be used for the protection and delivery of different functional lipids. Several methods exist for the adequate release of bioactive compounds included in nanoparticles, including oral delivery, inhalation, and intravenous injection. The biodistribution of intravenously injected nanoparticles is mainly influenced by 
their particle size and surface characteristics. The smallest particles $(20-30 \mathrm{~nm})$ are the first to be removed by renal excretion. Larger particles $(50-300 \mathrm{~nm})$ are captured by the mononuclear phagocytic system cells, although some of them can escape from the circulation through fenestrations of the endothelial barrier. The size requirements for the nanoparticles are strongly dependent on the target organ. For example, the ideal size requirements for nanoparticles developed for cancer treatment are between 70 and $200 \mathrm{~nm}$ (Gaumet et al., 2008). On the other hand, many authors agree that because nanoparticles have a solid matrix, they only will be able to remain in the circulatory system for longer periods in a size range between 100 and $200 \mathrm{~nm}$ (Langer et al., 2003). In the case of oral delivery, most administered particles are not retained and instead experience direct transit through the gastrointestinal tract (Ensign et al., 2012), with the exception of most protein nanoparticles, which will be degraded by the enzymes of the gastrointestinal tract unless they are coated with some protective agent. Hydrophobicity is another very important factor to be considered in the case of nanoparticles designed for oral delivery. Increased residence time in the gastrointestinal tract can be achieved by increasing hydrogen bonding or hydrophobic interactions, which favor mucus adherence and crossing of the mucus layer (Plapied et al., 2011). Hydrophobicity is also a major determinant in the absorption of the particles by Peyer's patches in the ileum (Ensign et al., 2012).

Two main methods exist to prepare protein nanoparticles: emulsification and desolvation. Emulsification methods have the disadvantage of the use of organic solvents for removal of the lipid residues and emulsifiers used in the process. A good alternative is the desolvation method, which is derived from the coacervation method of microencapsulation (Jahanshahi and Babaei, 2008). The method takes advantage of the desolvation that occurs upon addition of an agent such as alcohol or acetone or an inorganic salt in high concentrations. This addition normally leads to coacervation, and microcapsules are formed by this process. However, if the addition of the desolvating agent is stopped shortly before phase separation occurs, the molecules, which are in a tightly packed, rolled-up conformation, can be crosslinked with glutaraldehyde so this structure can be maintained and nanoparticles formed (Kreuter, 2007). This method has been used previously for preparation of gelatin (Coester et al., 2000), human serum albumin (Weber et al., 2000), BSA (Bansal et al., 2011), bovine $\beta$-LG (Gunasekaran et al., 2007), and bovine $\alpha$-LA (Mehravar et al., 2009) nanoparticles. Most of the nanoparticles prepared in this way have subcellular size and so have potential to deliver functional substances and especially poorly soluble substances such as functional lipids or hydrophobic antioxidants inside the cells (Mehravar et al., 2009). Whey protein nanospheres prepared by a thermal aggregation process are internalized when placed in contact with Caco-2 cells (Chen et al., 2006). These experiments suggest that whey protein nanoparticles could be internalized by cells and degraded there to liberate active substances (Chen et al., 2006). The properties of protein nanoparticles prepared by the desolvation method are affected by several factors, some of which $(\mathrm{pH}$ value, temperature, and agitation speed) have been previously studied in the case of $\alpha$-LA (Mehravar et al., 2011). Jun et al. (2011) proposed the hypothesis that hydrophobic interactions are fundamental to control the size of BSA nanoparticles. They varied the BSA concentration, $\mathrm{pH}$, and $\mathrm{NaCl}$ content to decrease hydrophobic interactions and the size of the BSA nanoparticles. These interactions, then, could be increased by different methods such as a change in desolvating agent or by treating the protein to unfold it partially. If the above hypothesis is correct, the size of the nanoparticles should increase. Solvents with a low polarity index usually favor hydrophobic interactions and should produce larger protein nanoparticles. In the case of $\alpha$-LA, some methods, such as heating, are known to cause protein unfolding (Wehbi et al., 2005). Furthermore, treatments such as high hydrostatic pressure (HHP) have a strong influence on the structure (particularly tertiary structure), surface hydrophobicity (Rodiles-López et al., 2010), and functional properties (Rodiles-López et al., 2008) of $\alpha$-LA, so nanoparticle-forming capacity could also be affected if it depends on the tertiary structure of the protein. The hypothesis of this work was that an increase in hydrophobic interactions should increase the size of the $\alpha$-LA nanoparticles obtained by the desolvation method and could have a strong influence on their structure and properties. Even though previous studies have been performed with $\alpha$-LA, the goal of obtaining nanoparticles in a size range of 100 to $200 \mathrm{~nm}$ remains unfulfilled. Nanoparticles in the size range of 210 to $213 \mathrm{~nm}$ were obtained by Mehravar et al. (2009, 2011) using acetone as desolvating agent. An additional objective of this work was, therefore, to obtain $\alpha$-LA nanoparticles in the 100 to $200 \mathrm{~nm}$ size range so that they could be used as carriers of bioactive compounds, as recommended by Langer et al. (2003).

\section{MATERIALS AND METHODS}

\section{Protein Sample}

BioPURE $\alpha$-LA (production batch JE 005-8-410) was kindly donated by Davisco Foods International Inc. 
(Eden Prairie, MN). The composition of the sample provided by the supplier was as follows: moisture content, $5.5 \%$; protein, $95 \%$ (91\% of this protein corresponded to $\alpha$-LA); fat, $0.5 \%$; carbohydrates, $0.5 \%$; and ash, $2.5 \%$.

\section{Heat and High-Pressure Pretreatments}

$\alpha$-Lactalbumin at a concentration of $2 \%$ (wt/vol) was treated at $60^{\circ} \mathrm{C}$ for $30 \mathrm{~min}$ before the desolvation process. $\alpha$-Lactalbumin at a concentration of $5 \%$ (wt/vol) in distilled water was treated with $\mathrm{HHP}$ at $600 \mathrm{MPa}$ and $55^{\circ} \mathrm{C}$ for $10 \mathrm{~min}$, as previously described (RodilesLópez et al., 2010).

\section{Preparation of $\alpha-L A$ Nanoparticles}

The $\alpha$-LA nanoparticles were prepared by adaptation of a previously described desolvation technique (Vogel et al., 2002). Briefly, $\alpha$-LA (40 mg) was dissolved in 2 $\mathrm{mL}$ of deionized water followed by desolvation of the protein solution by controlled $(1 \mathrm{~mL} / \mathrm{min})$ dropwise addition of $8 \mathrm{~mL}$ of a desolvating agent (ethanol, isopropanol, or acetone) with constant stirring (500 rpm). Immediately after the desolvation step, $2 \mathrm{~mL}$ of $8 \%$ aqueous glutaraldehyde solution was added to achieve $\alpha$-LA cross-linking. After stirring for $3 \mathrm{~h}$, the resulting nanoparticles were purified by 5 cycles of centrifugation $\left(25,000 \times g, 30 \mathrm{~min}, 4^{\circ} \mathrm{C}\right)$, and the pellet was redispersed in a $10 \mathrm{mM} \mathrm{NaCl}$ solution (pH 9) to the original volume by ultrasonication in a bath-type sonicator. All preparations were performed at room temperature $\left(25^{\circ} \mathrm{C}\right)$.

\section{Determination of the Nondesolvated $\alpha-L A$ After Desolvation}

The amount of $\alpha$-LA that was not assembled into nanoparticles was determined directly after the crosslinking step. The nanoparticles were separated from the supernatant by centrifugation at $16,000 \times g$ for $20 \mathrm{~min}$ at room temperature $\left(25^{\circ} \mathrm{C}\right)$. An aliquot of the supernatant $(100 \mu \mathrm{L})$ was diluted with $900 \mu \mathrm{L}$ of water, and the amount of dissolved $\alpha$-LA in the supernatant was determined by a standard bicinchoninic acid (BCA) protein assay (Smith et al., 1985) using the Pierce BCA Protein Assay Kit 23225 (Thermo Fisher Scientific Inc., Rockford, IL). To $50 \mu \mathrm{L}$ of the supernatant, 1,000 $\mu \mathrm{L}$ of the BCA working reagent was added. After incubating the solution at $37^{\circ} \mathrm{C}$ for $30 \mathrm{~min}$, the samples were measured spectrophotometrically at $562 \mathrm{~nm}$. The protein contents of the samples and the initial $\alpha$-LA solution were calculated by interpolation on a previously prepared $\alpha$-LA standard curve (Langer et al., 2003).

\section{Transmission Electron Microscopy}

The morphology of nanoparticles was examined using a JEM1010 transmission electron microscope (Jeol, Tokyo, Japan) at a voltage of $60 \mathrm{kV}$. The aqueous dispersion of the nanoparticles was diluted 10 times, and $5 \mu \mathrm{L}$ was drop-casted onto a formvar carbon-coated copper grid (200 mesh), and the grid was air-dried at room temperature before loading into the microscope.

\section{Protein Nanoparticle Size and Distribution}

The size and distribution of the prepared $\alpha$-LA were analyzed by dynamic light scattering (DLS) using a Zetasizer Nano ZS90 (Malvern Instruments Ltd., Malvern, UK). This technique is extensively used as an adequate way of measuring particle sizes in the range from a few nanometers up to 1 or $2 \mu \mathrm{m}$. Because DLS measures the apparent hydrodynamic radius of particles, it is not only suitable for determining the basic size of particles, but it can also detect changes in size as a consequence of processing (Alexander and Dalgleish, 2006). The nanoparticle samples were diluted 1:400 with deionized water and measured at a temperature of $25^{\circ} \mathrm{C}$ and a scattering angle of $90^{\circ}$.

\section{Molecular Weight}

This property could be used to calculate approximately how many monomeric units of $\alpha$-LA comprise the nanoparticles. Molecular weight (MW) was also determined with the Zetasizer Nano ZS90 equipment using static light scattering. The nanoparticle suspension was sonicated for $30 \mathrm{~min}$ and diluted to a $20 \mu \mathrm{g}$ of protein/L of distilled water before measuring the MW.

\section{$\zeta$-Potential}

$\zeta$-Potential describes the surface charge property of nanoparticles. It indicates the electrical potential of particles and is influenced by the composition of the particle and the medium in which it is dispersed. Nanoparticles with a $\zeta$-potential outside the range of $\pm 30 \mathrm{mV}$ are stable in suspension because the surface charge inhibits aggregation of the particles (Mohanraj and Chen, 2006). Titration experiments on the nanoparticles were performed over a $\mathrm{pH}$ range between 3 and 9 using the Malvern Zetasizer Nano ZS90 together with an autotitrator provided with the equipment. For the analysis, the samples were diluted 1:400 with deionized water, the $\mathrm{pH}$ value of the suspension was automatically adjusted by the titration unit, and the $\zeta$-potential was measured by the Zetasizer Nano ZS90. 


\section{Surface Hydrophobicity}

The number and relative size of hydrophobic spots on the surface of a protein play a key role in its solubility and tendency to aggregate under defined conditions of $\mathrm{pH}$, temperature, and ionic strength. The binding of the nonpolar fluorescent dye l-anilinonaphthalene8-sulphonate (ANS) to the hydrophobic sites of proteins was used to evaluate the surface hydrophobicity of the $\alpha$-LA nanoparticles (Cardamone and Puri, 1992). Nanoparticle suspensions at a concentration of $2 \mathrm{mg} /$ $\mathrm{mL}$ were prepared in $0.1 \mathrm{M}$ phosphate buffer, $\mathrm{pH} 7$. Seventy-five microliters of this suspension was mixed with $25 \mu \mathrm{L}$ of $15 \mathrm{~m} M$ ANS solution and diluted to $3 \mathrm{~mL}$

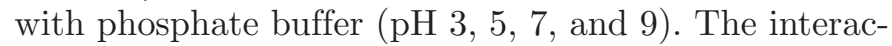
tion of ANS with the nanoparticles was analyzed with an ISS K2 spectrofluorometer (ISS Inc., Champaign, IL). The measurements were made in $10-\times 10-\mathrm{mm}$ cuvettes at a controlled temperature $\left(25^{\circ} \mathrm{C}\right)$ with stirring. Excitation of ANS was performed at $380 \mathrm{~nm}$ and emission measured from 400 to $600 \mathrm{~nm}$. The surface hydrophobicity results were given in arbitrary units (a.u.) by the equipment software.

\section{In Vitro Gastrointestinal Simulation of Nanoparticle Digestibility}

Incorporation of bioactive compounds into food systems via nanoparticles involves oral administration and uptake of the compound at the intestinal level. Therefore, many studies have been conducted to develop biodegradable nanoparticles to deliver safely these nutraceuticals to the intestine (Singh et al., 2010). In this case, we used an in vitro method that attempts to simulate in vivo gastric and small intestinal transit in the absence of bile salts (Charteris et al., 1998), with some modifications. Simulated gastric and pancreatic juices were prepared by suspending $3 \mathrm{~g} / \mathrm{L}$ of pepsin (P-7000, Sigma-Aldrich Inc., St. Louis, MO) or $1 \mathrm{~g} / \mathrm{L}$ of pancreatin (P-7545, Sigma-Aldrich Inc.) in sterile saline solution $(0.85 \% \mathrm{wt} / \mathrm{vol})$ and adjusting the $\mathrm{pH}$ to 2 or 8 with concentrated $\mathrm{HCl}$ or $0.1 \mathrm{M} \mathrm{NaOH}$. To $0.5 \mathrm{~mL}$ of nanoparticle suspension was admixed $1 \mathrm{~mL}$ of simulated gastric or pancreatic juice. The materials were vortexed and incubated at $37^{\circ} \mathrm{C}$ with constant agitation $(150 \mathrm{rpm})$ in a controlled-environment incubator shaker (New Brunswick Scientific, Edison, NJ). The samples were incubated for $1 \mathrm{~h}$ for the gastric digestion assay and $4 \mathrm{~h}$ for the intestinal simulation. The changes in the structure of the nanoparticles were analyzed by transmission electron microscopy (TEM) as previously described.

\section{Antioxidant Capacity of the Nanoparticles}

Antioxidant activity was determined by the 2,2'-azinobis-3-ethyl-benzothiozoline-6-sulfonic acid (ABTS) radical-scavenging assay. The blue/green radical monocation of $\mathrm{ABTS} \bullet^{+}$chromophore is generated by oxidation of ABTS with potassium persulfate and is reduced in the presence of hydrogen-donating antioxidants. Thus, the degree of decoloration as percentage inhibition of the radical is calculated as a function of concentration and time relative to the activity of a standard such as Trolox (Re et al., 1999). The ABTS radical cation was produced by mixing a $7 \mathrm{~m} M$ ABTS solution with $2.45 \mathrm{~m} M$ potassium persulfate and allowing the mixture to stand protected from light at room temperature $\left(25^{\circ} \mathrm{C}\right)$ for 12 to $16 \mathrm{~h}$. The radical solution was then diluted with PBS, pH 7.4, to an absorbance of 0.70 at $734 \mathrm{~nm}, 2 \mathrm{~mL}$ of this solution was mixed with 50 $\mu \mathrm{L}$ of nanoparticle solution, and the absorbance at 734 $\mathrm{nm}$ was read $1 \mathrm{~min}$ after initial mixing and up to $7 \mathrm{~min}$. The assay was performed in triplicate using Trolox as a standard. The results of the assay were expressed relative to Trolox in terms of Trolox-equivalent antioxidant capacity (TEAC). The antioxidant capacities of $\alpha$-LA and HHP-treated $\alpha$-LA were also determined before the desolvation process.

\section{Statistical Analysis}

The influence of the type of desolvating agent (ethanol, isopropanol, or acetone) and protein unfolding pretreatment (heat or HHP treatment) on nanoparticle size was analyzed by a 2-way ANOVA using Excel 2003 (Microsoft Corp., Redmond, WA).

\section{RESULTS AND DISCUSSION}

The desolvation of proteins with organic solvents followed by cross-linking with glutaraldehyde is a common method for the formation of protein nanoparticles. In this work, we studied the effects of increasing the hydrophobic interactions by varying some preparation parameters on the nanoparticle properties. Parameters such as the pretreatment of the protein before the desolvation process (heat or HHP treatment) and type of organic solvent (ethanol, isopropanol, or acetone) were changed.

\section{Particle Size}

We studied the effect of pretreatment and solvent on particle size and polydispersity index, where polydispersity, in the field of light scattering, is used to describe 


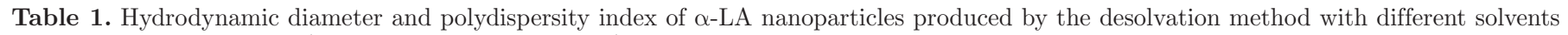
and protein pretreatments (none, heat, or high pressure)

\begin{tabular}{|c|c|c|c|c|c|}
\hline Pretreatment & $\begin{array}{l}\text { Organic } \\
\text { solvent }\end{array}$ & $\begin{array}{l}\text { Hydrodynamic } \\
\text { diameter }(\mathrm{nm})\end{array}$ & $\begin{array}{l}\text { Polydispersity } \\
\text { index }\end{array}$ & $\begin{array}{c}\text { Molecular } \\
\text { weight (Da) }\end{array}$ & $\begin{array}{l}\text { Number of } \\
\alpha \text {-LA units }\end{array}$ \\
\hline None & Ethanol & 246 & 0.214 & $3.96 \times 10^{9}$ & 282,857 \\
\hline None & Isopropanol & 324.9 & 0.179 & $2.7 \times 10^{9}$ & 192,857 \\
\hline None & Acetone & 152.3 & 0.166 & $1.74 \times 10^{9}$ & 124,286 \\
\hline $60^{\circ} \mathrm{C}, 30 \mathrm{~min}$ & Ethanol & 205.1 & 0.121 & $4.14 \times 10^{9}$ & 295,714 \\
\hline $60^{\circ} \mathrm{C}, 30 \mathrm{~min}$ & Isopropanol & 293.4 & 0.088 & $1.37 \times 10^{9}$ & 97,857 \\
\hline $60^{\circ} \mathrm{C}, 30 \mathrm{~min}$ & Acetone & 163.1 & 0.104 & $1.07 \times 10^{9}$ & 76,429 \\
\hline $600 \mathrm{MPa}, 55^{\circ} \mathrm{C}, 30 \mathrm{~min}$ & Ethanol & 245.8 & 0.302 & $7.44 \times 10^{9}$ & 531,429 \\
\hline $600 \mathrm{MPa}, 55^{\circ} \mathrm{C}, 30 \mathrm{~min}$ & Isopropanol & 298.4 & 0.383 & $4.27 \times 10^{9}$ & 305,000 \\
\hline $600 \mathrm{MPa}, 55^{\circ} \mathrm{C}, 30 \mathrm{~min}$ & Acetone & 207.6 & 0.169 & $1.39 \times 10^{9}$ & 99,286 \\
\hline
\end{tabular}

the width of the nanoparticle size distribution. A lower polydispersity index indicates a narrower size distribution; usually, samples with a polydispersity index less than $\sim 0.2$ are considered monodisperse. Particle size was measured as the hydrodynamic diameter, the effective size of the molecule as detected by its diffusion using DLS. The results of this experiment are shown in Table 1. It can be seen that most nanoparticle preparations (with the exception of the nanoparticles formed after the HHP treatment of the protein and desolvation with ethanol and isopropanol) could be considered monodisperse. These results are similar to those obtained by Langer et al. (2003) and Azarmi et al. (2006) during preparation by desolvation and crosslinking of human serum albumin and gelatin nanoparticles, respectively.

The morphology of the prepared $\alpha-L A$ nanoparticles was examined with TEM and, according to this technique, all particles were essentially spherical, independent of the desolvating conditions used (Figure 1). This is a common feature of albumin and other protein nanoparticles (Vogel et al., 2002). Particle size is a very important characteristic of protein nanoparticles and only a few studies are available in which size control has been studied (Desai et al., 1996; Jun et al., 2011). In this study, $\alpha$-LA nanoparticles were in the range of 152 to $325 \mathrm{~nm}$. Other studies have shown that the size of nanoparticles prepared from whey proteins using the desolvation method is in the range of 155 to $390 \mathrm{~nm}$, depending on the conditions of preparation and the type of organic solvent used (Gunasekaran et al., 2007; Mehravar et al., 2009; Singh et al., 2010). The effect of the type of desolvating agent and protein unfolding treatment on the nanoparticle size was analyzed by a 2 -way ANOVA applied to the data in Table 1. The results indicated a highly significant effect of the type of desolvating agent $(P=0.005)$ and a nonsignificant effect of the protein unfolding pretreatment $(P=0.34)$. The effect of the type of solvent (acetone or ethanol) on particle size has been studied previously in the case of gelatin (Azarmi et al., 2006) and $\alpha$-LA (Mehravar et al., 2009) nanoparticles. In both cases, acetone was selected as the best solvent because it produced smaller nanoparticles than ethanol. In this study, as in the other studies, for all nanoparticles (with or without pretreatment), acetone produced the smallest nanoparticles, followed by ethanol and isopropanol. The solvents used in this study fall into 2 categories: polar protic (ethanol and isopropanol) and polar aprotic (acetone). Alcohols are good hydrogen bond donors and acceptors, whereas acetone is not a donor, only an acceptor (Morrison and Boyd, 1992). This could indicate that the presence of hydrogen bonding favors the formation of larger lattices and consequently of larger nanoparticles. However, the ability of these compounds to interact hydrophobically is also very important. Two parameters are used to compare the polarity of solvents and both are correlated: the dielectric constant $(\mathbf{D})$ and the polarity index (PI). The less-polar alcohol is isopropanol, with a D value of 20 and a PI of 3.9, whereas ethanol has an intermediate polarity with a D value of 25 and a PI of 6.0 (Snyder, 1978). These values support our hypothesis, because the lower the polarity of the desolvating agents, the larger the hydrophobic interactions and the greater the size of the nanoparticles obtained. On the other hand, acetone, as an aprotic solvent, is not able to form hydrogen bonds and has a $\mathrm{D}$ value of 21 and a PI of 5.1. The polarity of this solvent is intermediate between that of the 2 alcohols and yet forms the smaller nanoparticles. This could indicate that 2 important characteristics of a desolvating agent to be able to produce large nanoparticles $(\geq 293 \mathrm{~nm})$ are (1) its ability to form hydrogen bonds and (2) low polarity so it can generate, additionally, hydrophobic interactions. Based on these characteristics, isopropanol could be recommended as the solvent of choice whenever nanoparticles of around $300 \mathrm{~nm}$ are to be produced. The application of a thermal pretreatment $\left(60^{\circ} \mathrm{C}, 30 \mathrm{~min}\right)$ on $\alpha$-LA decreased the average size of the nanoparticles by 16.7 and $9.7 \%$ when ethanol and isopropanol, respectively, were used as desolvat- 
ing agents. In the case of acetone, a $7.1 \%$ increase in size was observed. However, thermal pretreatment produced a decrease in polydispersity in all cases, resulting in more homogeneous preparations. Similar behavior (smaller particle size and polydispersity) was observed during the preparation of $\beta$-LG nanoparticles by the desolvation method using acetone and preheating at $60^{\circ} \mathrm{C}$ for $30 \mathrm{~min}$ (Gunasekaran et al., 2007). The use of HHP (600 MPa, $\left.55^{\circ} \mathrm{C}, 30 \mathrm{~min}\right)$ as a pretreatment had no effect in the particle size when ethanol was used as desolvatant; however, for isopropanol and acetone, a decrease of $8.2 \%$ and an increase of $36.3 \%$, respectively, in particle size were observed. Nevertheless, as mentioned above, the effect of the protein unfolding pretreatments on particle size was nonsignificant $(P>0.05)$, indicating that these methods did not increase hydrophobic interactions to a level of importance for a change in size to occur. It has been shown (Rodiles-López et al., 2010) that HHP treatments induce changes in the tertiary structure of $\alpha$-LA, so these results indicate that tertiary structure is not very important for $\alpha$-LA to be able to form nanoparticles. It is important to note that a significant increase in polydispersity, which leads to the formation of polydisperse suspensions, was observed with acetone and isopropanol. These artificial systems of dairy nanoparticles are, however, more homogeneous than the natural system (casein micelles) present in milk; casein micelles have an average size of $130 \mathrm{~nm}$ and high polydispersity (0.50) as measured by DLS (Müller-Buschbaum et al., 2007). One of the main aspects in preparing a colloidal bioactive compound carrier system has to be establishing process conditions that control the resultant particle size and that lead to the formation of particles with a narrow size distribution of approximately 100 to $200 \mathrm{~nm}$ (Langer et al., 2003). In our study, the nanoparticles prepared using acetone would be adequate bioactive compound carriers because they were in a size range of 152.3 to 207.6 $\mathrm{nm}$. This is the first time that $\alpha$-LA nanoparticles in this size range have been obtained. Using the standard BCA protein assay, an average particle yield of 99.63 $\pm 0.37 \%$ was determined. This yield was independent of the desolvating agent used and the use, or not, of a pretreatment. This yield is higher than that obtained by Langer et al. (2003) in the case of human serum albumin nanoparticles (95\%).

\section{Molecular Weight}

Table 1 shows the molecular weight and the number of $\alpha$-LA units of nanoparticles produced by the desolvation method with different solvents and protein pretreatments. The particles prepared with ethanol as desolvating agent and HHP as pretreatment showed the highest MW $\left(7.44 \times 10^{9} \mathrm{Da}\right)$ and number of monomer units $(531,429)$, whereas those prepared with acetone and a thermal pretreatment presented the smallest MW $\left(1.07 \times 10^{9} \mathrm{Da}\right)$ and number of $\alpha$-LA units $(76,429)$. A very low correlation $(\mathrm{r}=0.27)$ was found between particle size and MW. This could be because size was determined by DLS (also known as photon correlation spectroscopy or PCS), which uses scattered light to measure the rate of diffusion of the protein particles. These motion data are processed to derive a size distribution for the sample, where the size is given by the Stokes radius or hydrodynamic radius (or diameter) of the protein nanoparticle. This hydrodynamic size depends on both mass and shape (conformation). As such, the particle size calculated from the diffusional properties of the particle is suggestive of the apparent size of the dynamic hydrated or solvated particle (Alexander and Dalgleish, 2006). On the other hand, the absolute MW of protein particles was determined by static light scattering because protein particles are able to scatter light isotropically and the scattering pattern exhibits no angular dependence (Bloomfield, 2000).

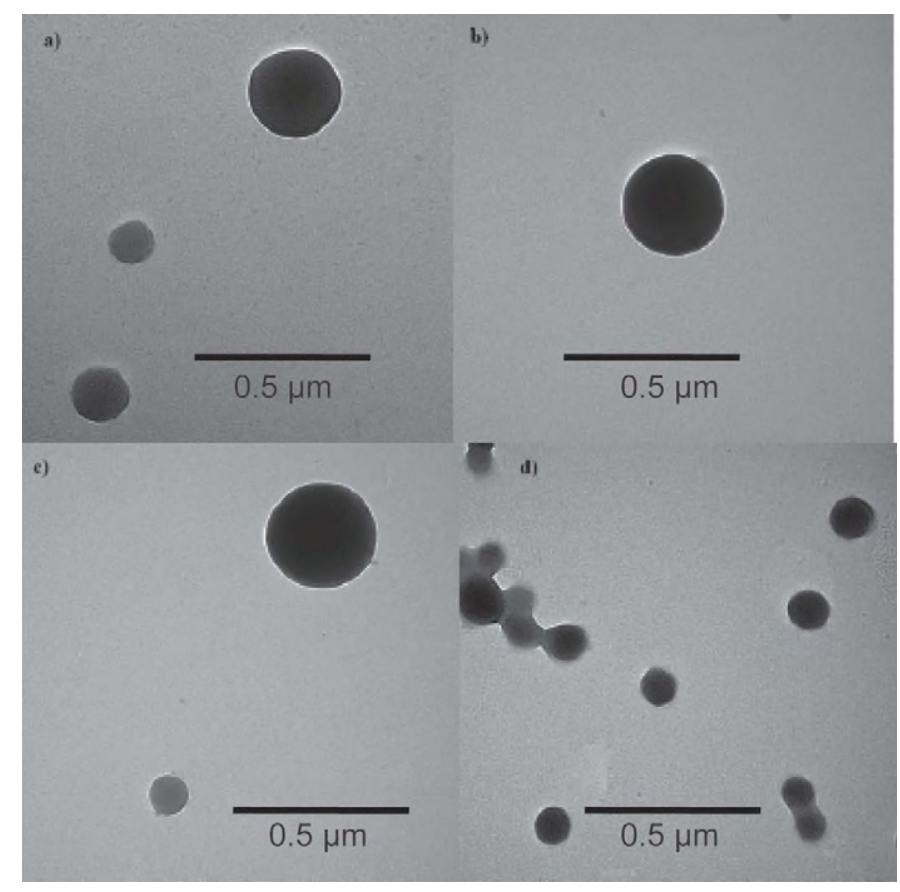

Figure 1. Transmission electron microscopy of $\alpha$-LA nanoparticles prepared by the method of desolvation with an organic solvent and a pretreatment. a) Ethanol and no pretreatment; b) acetone and high-pressure treatment $\left(600 \mathrm{MPa}, 55^{\circ} \mathrm{C}, 30 \mathrm{~min}\right)$; c) isopropanol and no pretreatment; d) ethanol and heat treatment $\left(60^{\circ} \mathrm{C}, 30 \mathrm{~min}\right)$. Magnification: 100,000×. 


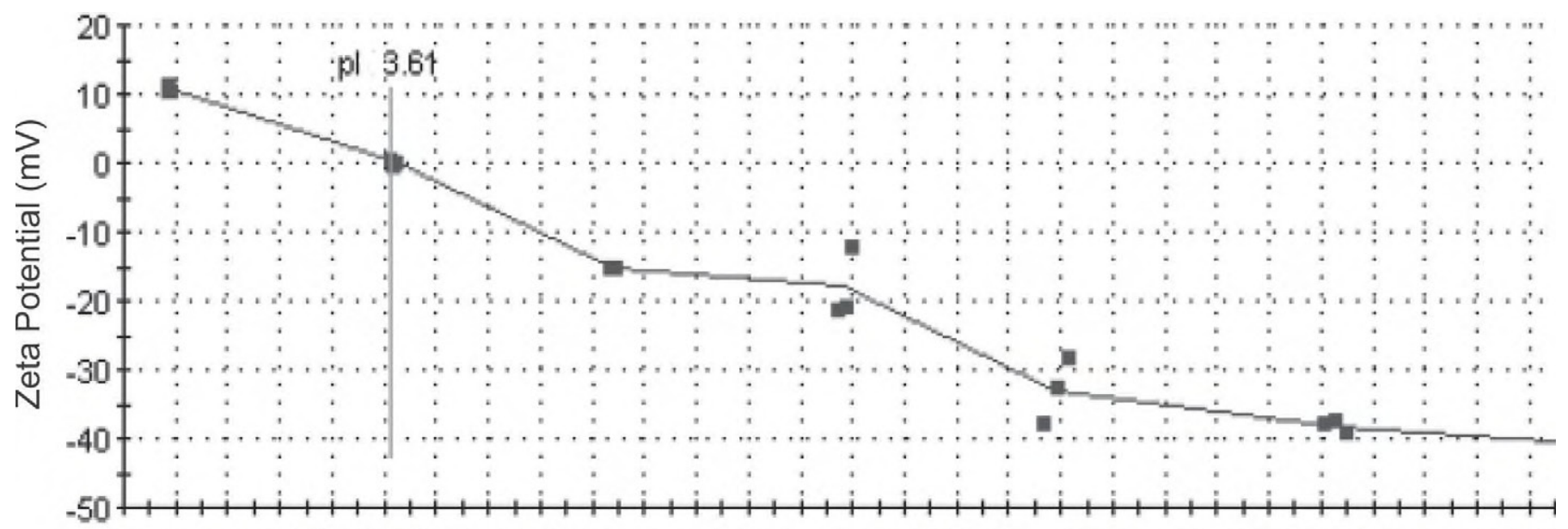

$\mathrm{pH}$

Figure 2. Isoelectric titration graph of $\alpha$-LA nanoparticles prepared with acetone and without pretreatment. $\mathrm{pI}=$ isoelectric point.

\section{$\zeta$-Potential}

Figure 2 shows the typical plot of $\zeta$-potential versus $\mathrm{pH}$ for $\alpha$-LA nanoparticles prepared with acetone as desolvating agent and without any pretreatment. It can be observed that $\zeta$-potential decreases when $\mathrm{pH}$ increases. The surface of the $\alpha$-LA nanoparticles is positively charged below the isoelectric point $(\mathbf{p I})$ and negatively charged above this point. According to the graph, the $\mathrm{pI}$ of the $\mathrm{\alpha}$-LA nanoparticles was 3.61, whereas the $\mathrm{pI}$ of the native $\alpha$-LA is 4.2 (Bramaud et al., 1997), indicating a shift to a lower value when the protein forms the nanoparticles. This could indicate that more hydrophilic groups with a negative charge are exposed in the surface of the nanoparticle structure compared with the native protein and more acid is needed to neutralize them. It is possible that these negatively charged species were originally solvated by the partial positive dipole of the acetone. The plot predicts that the nanoparticle suspension should be stable at $\mathrm{pH}$ values above $4.8(\zeta$-potential $\leq-30 \mathrm{mV})$ and that problems with stability would be expected at $\mathrm{pH}$ values between 3 and 4.8. $\beta$-Lactoglobulin nanoparticles, with a $\mathrm{pI}$ of 5.1 , are stable only at $\mathrm{pH}$ values above 6.5 (Gunasekaran et al., 2007), so the $\alpha$-LA nanoparticles are a better option for use in foods due to their wider range of $\mathrm{pH}$ stability. Table 2 shows the $\mathrm{pI}$ and $\mathrm{pH}$ stability ranges of $\alpha$-LA nanoparticles produced by the desolvation method with different solvents and protein pretreatments. Depending on the combination of desolvating agent and pretreatment, $\alpha$-LA nanoparticles of different $\mathrm{pH}$ stability ranges and sizes can be obtained to fit the needs for different applications of the food processor. Some natural protein nanoparticles, such as the casein micelles, are not as stable as the $\alpha$-LA nanoparticles in this study, because they have a $\zeta$-potential of $-18 \mathrm{mV}$ measured at natural $\mathrm{pH}$ in skim milk (Wade et al., 1996).

\section{Surface Hydrophobicity}

In this field, surface hydrophobicity could be an indication of the tendency of the hydrophobic spots on the surface to bind nonpolar amino acid groups of unfolded polypeptide chains, with consequent aggregation and increase in nanoparticle size. Table 3 shows the values of surface hydrophobicity (extrinsic fluorescence) of $\alpha$-LA nanoparticles produced by the desolvation method with different solvents and protein pretreatments at $4 \mathrm{pH}$ values. No significant correlation could be found between the sizes (Table 1) and surface hydrophobicities at different $\mathrm{pH}$ values for the $\alpha$-LA nanoparticles prepared under different conditions. The highest positive value of surface hydrophobicity was obtained for nanoparticles prepared with ethanol and HHP as a pretreatment and measured at $\mathrm{pH} 3$. Such particles could be very useful as active compounds carriers because hydrophobicity is a key factor for the absorption of the particles by Peyer's patches (Ensign et al., 2012). The highest negative value of surface hydrophobicity was obtained, again at $\mathrm{pH} 3$, for particles prepared with isopropanol and HHP. The size of both nanoparticles was similar. Further investigations are needed to understand the exact role of surface hydrophobicity on the size and stability of $\alpha-\mathrm{LA}$ nanoparticles. 
Table 2. Isoelectric point $(\mathrm{pI})$ and $\mathrm{pH}$ stability range of $\alpha-\mathrm{LA}$ nanoparticles produced by the desolvation method with different solvents and protein pretreatments (none, heat, or high pressure)

\begin{tabular}{llcc}
\hline Pretreatment & Organic solvent & pI & pH stability range \\
\hline None & Ethanol & 3.90 & $\geq 5.4$ \\
None & Isopropanol & 3.41 & $\geq 5.1$ \\
None & Acetone & 3.61 & $\geq 4.8$ \\
$60^{\circ} \mathrm{C}, 30 \mathrm{~min}$ & Ethanol & $<3.00$ & $\geq 6.8$ \\
$60^{\circ} \mathrm{C}, 30 \mathrm{~min}$ & Isopropanol & $<3.00$ & $\geq 6.0$ \\
$60^{\circ} \mathrm{C}, 30 \mathrm{~min}$ & Acetone & 3.72 & $\geq 5.5$ \\
$600 \mathrm{MPa}, 55^{\circ} \mathrm{C}, 30 \mathrm{~min}$ & Ethanol & 3.75 & $\geq 5.5$ \\
$600 \mathrm{MPa}, 55^{\circ} \mathrm{C}, 30 \mathrm{~min}$ & Isopropanol & $<3.00$ & $\geq 5.8$ \\
$600 \mathrm{MPa}, 55^{\circ} \mathrm{C}, 30 \mathrm{~min}$ & Acetone & 3.55 & $\geq 6.0$ \\
\hline
\end{tabular}

\section{In Vitro Nanoparticle Digestion}

The enzymatic degradation of protein nanoparticles intended to be used as delivery vehicles for bioactive compounds is an important factor in deciding the route of administration (Singh et al., 2010) and a prerequisite for intracellular release of bioactive compounds after uptake of the nanoparticle by the cell (Langer et al., 2008). In this current study, all $\alpha$-LA nanoparticles were degraded by both enzymatic systems (gastric and pancreatic) to form very small particles and debris. This degradation and size reduction was independent of the desolvating agent or pretreatment used in the preparation of the particles. Figures 3 and 4 show some examples of TEM observations of the results obtained with the simulated gastrointestinal digestion of the $\alpha-L A$ nanoparticles. Previous reports have indicated that BSA nanoparticles are sensitive to trypsin and pepsin even after being cross-linked with glutaraldehyde and that their stability could be improved by coating with poly-L-lysine (Singh et al., 2010). Similar degradation results were obtained for human serum albumin (Langer et al., 2008), where extensive crosslinking protected the nanoparticles against trypsin degradation; however, in the presence of pepsin, these particles were completely degraded after $30 \mathrm{~min}$. The results from this work and the studies cited above indicate that unless the protein nanoparticles are somehow protected, they will be easily degraded by the cellular proteolytic systems.

\section{Antioxidant Activity of the Nanoparticles}

The antioxidant capacity of many proteins depends on their amino acid composition. Cysteine and methionine possess the highest antioxidant activity of all the amino acids and they are involved in the scavenging of free radicals (Salami et al., 2009). Approaches to increase the exposure of antioxidant amino acids in proteins involve the disruption of their tertiary structure (i.e., partial denaturation) through temperature or high-pressure treatments or the use of enzymatic hydrolysis (Elias et al., 2008). The TEAC values found for $\alpha$-LA and HHP-treated $\alpha$-LA were 89.56 and $134.62 \mathrm{mmol}$ of Trolox equivalents/mL, respectively. This increase in antioxidant capacity is most likely due to the changes in tertiary structure brought about by the HHP treatment, as shown in a previous study (Rodiles-López et al., 2010). Table 3 shows the antioxidant capacity of $\alpha$-LA nanoparticles produced by the desolvation method with different solvents and protein pretreatments. As expected, with their increase in complexity, the protein nanoparticles had lower antioxidant

Table 3. Surface hydrophobicity (extrinsic fluorescence, arbitrary units) and antioxidant activity of $\alpha$-LA nanoparticles produced by the desolvation method with different solvents and protein pretreatments (none, heat, or high pressure) at $4 \mathrm{pH}$ values ${ }^{1}$

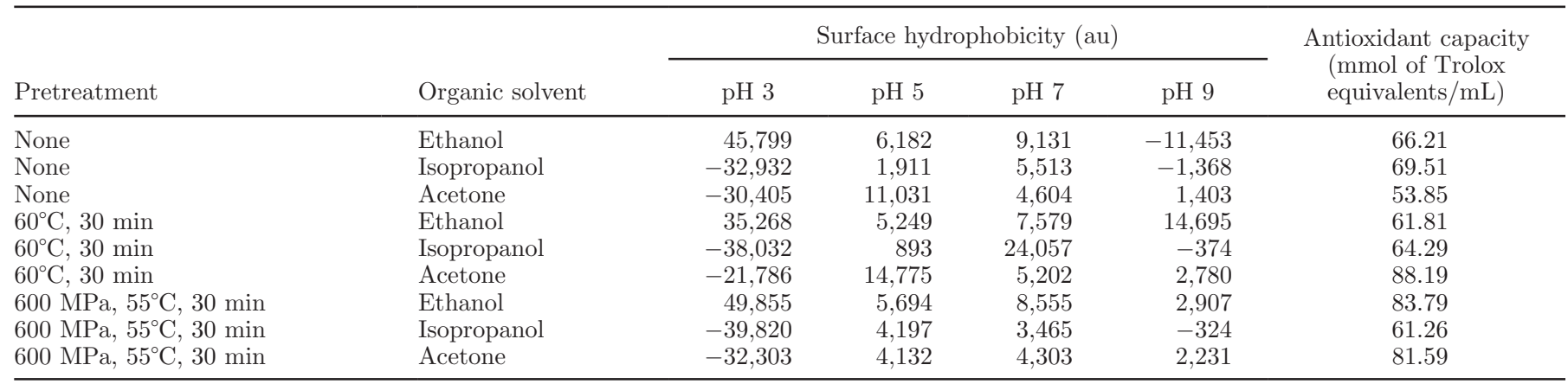

\footnotetext{
${ }^{1}$ Extrinsic 8-anilino-1-naphthalene sulfonate fluorescence.
} 


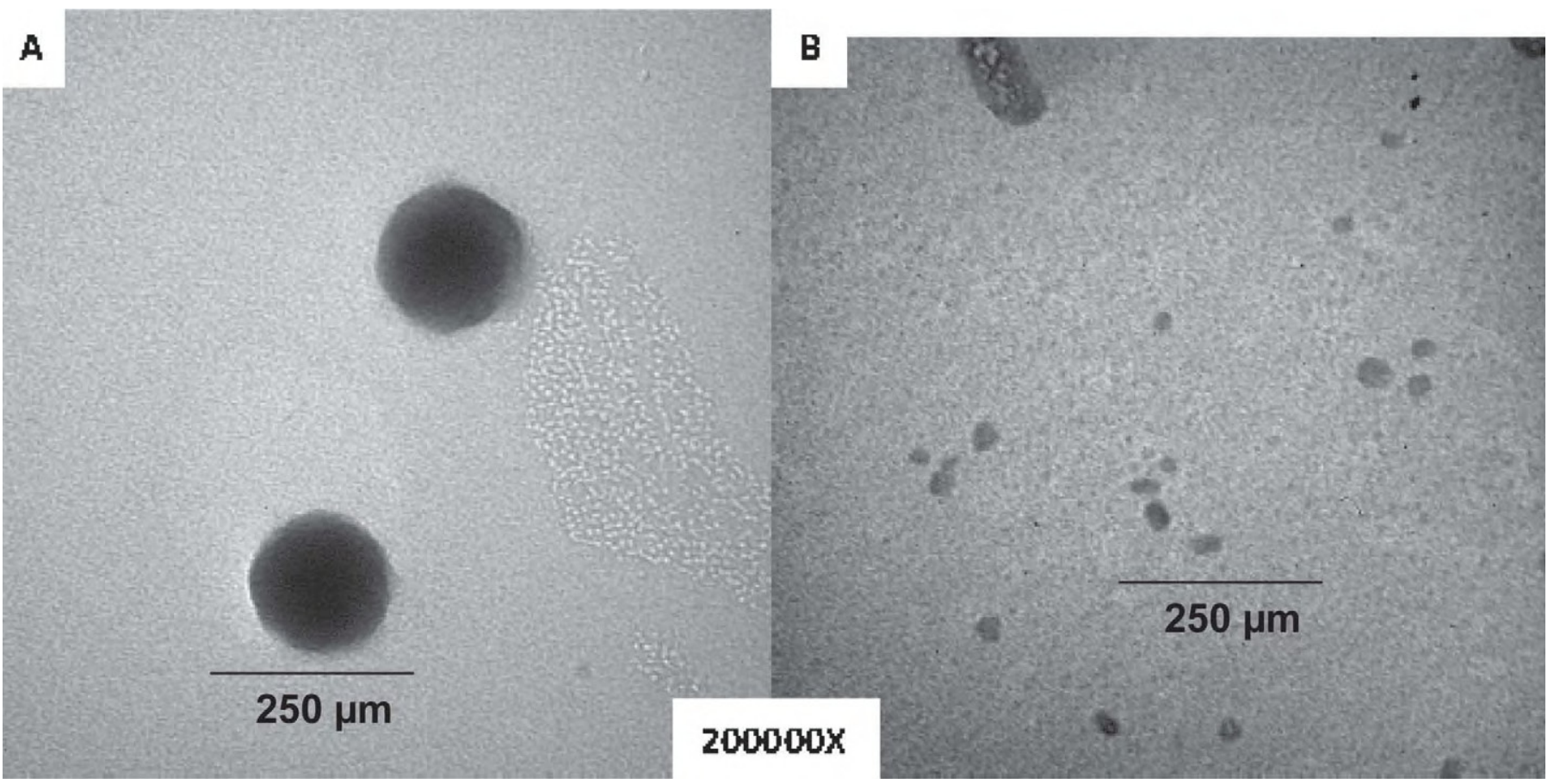

Figure 3. Transmission electron microscopy of the simulated gastric digestion of the $\alpha$-LA nanoparticles (prepared with ethanol and thermal pretreatment) with pepsin at $\mathrm{pH} 2$ after (A) $0 \mathrm{~h}$ and (B) $1 \mathrm{~h}$ of digestion.

\section{A}

B

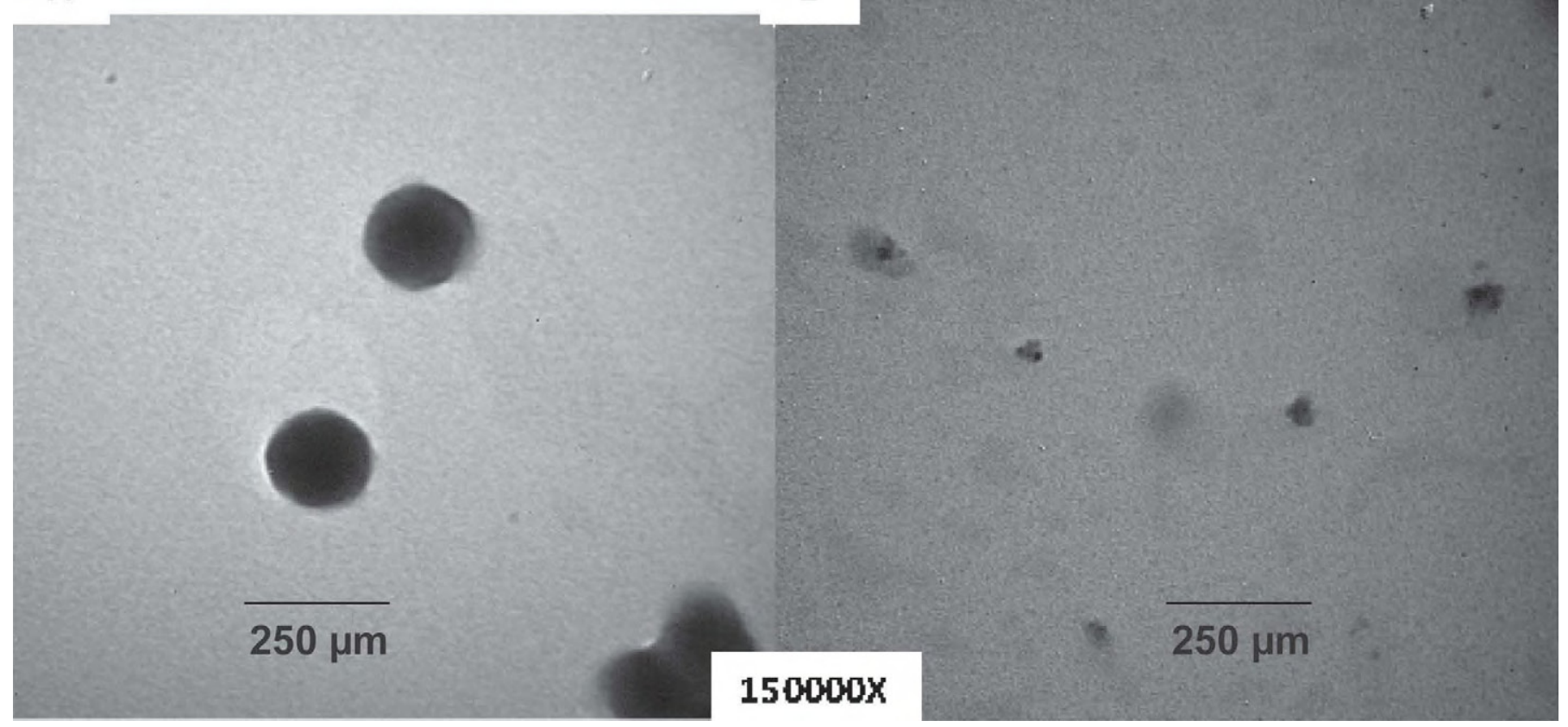

Figure 4. Transmission electron microscopy of the simulated intestinal digestion of the $\alpha$-LA nanoparticles (prepared with ethanol and thermal pretreatment) with pancreatin at $\mathrm{pH} 8$ after (A) $0 \mathrm{~h}$ and (B) $4 \mathrm{~h}$ of digestion. 
capacity than the protein monomers. This is more evident when no pretreatment was applied. The highest antioxidant capacity was obtained for the particles prepared with acetone and thermal pretreatment with $88.19 \mathrm{mmol}$ of Trolox equivalents/mL, a value similar to that obtained for $\alpha$-LA. These nanoparticles could thus be used to protect and deliver easily oxidizable compounds such as ascorbic acid or functional lipids. Slightly lower antioxidant capacities were obtained in the nanoparticles in which HHP was used as the pretreatment and acetone (81.59) or ethanol (83.79) was used as desolvating agents. A positive correlation has been found between ANS fluorescence and antioxidant activity in camel and bovine $\alpha$-LA (Salami et al., 2009). However, no significant correlation could be found for the $\alpha$-LA nanoparticles in the current study, indicating that that the surface hydrophobicity was likely due to amino acids such as tyrosine, tryptophan, or histidine, which have a weak free-radical scavenging activity, and not to methionine or cysteine (which is unavailable because it is involved in strong disulfide bonds).

\section{CONCLUSIONS}

The use of different desolvating agents and pretreatments in the desolvation process resulted in the formation of nanoparticles with a wide variety of properties. The tertiary structure of $\alpha$-LA is not important in the ability of this protein to form nanoparticles. The smallest particles can be obtained with the use of acetone and without any pretreatment, whereas the use of isopropanol produced the largest particles, indicating that an increase in hydrophobic interactions does lead to the formation of larger $\alpha$-LA nanoparticles. The smallest nanoparticles were also the most stable according to their $\zeta$-potential, although their antioxidant activity was the lowest. This is the first time that $\alpha-\mathrm{LA}$ nanoparticles with a suitable size range to be used for bioactive compounds carrier have been obtained. The use of HHP as pretreatment and ethanol as desolvating agent was useful in obtaining nanoparticles with high surface hydrophobicity, which might be absorbed by Peyer's patches. All types of nanoparticles were easily degraded by the proteolytic enzymes present in the gastrointestinal tract, so stabilizing coatings might be necessary if nanoparticles are to be used for delivery of bioactive compounds.

\section{ACKNOWLEDGMENTS}

This work was partially financed by the Instituto Politécnico Nacional (Mexico City, Mexico). J. Octavio Rodiles-López and Izlia J. Arroyo-Maya thank the Consejo Nacional de Ciencia y Tecnología (Mexico
City, Mexico) for the awarding of their scholarship. Gutiérrez-López and Hernández-Sánchez also acknowledge the fellowship from COFAA-IPN (Mexico City, Mexico). The help of María Esther Sánchez Espíndola (IPN) in the TEM experiments is greatly appreciated.

\section{REFERENCES}

Alexander, M., and D. G. Dalgleish. 2006. Dynamic light scattering techniques and their applications in food science. Food Biophys. $1: 2-13$.

Azarmi, S., Y. Huang, H. Chen, S. McQuarrie, D. Abrams, W. Roa, W. H. Finlay, G. G. Miller, and R. Löbenberg. 2006. Optimization of a two-step desolvation method for preparing gelatin nanoparticles and cell uptake studies in 143B osteosarcoma cancer cells. J. Pharm. Pharm. Sci. 9:124-132.

Bansal, A., D. N. Kapoor, R. Kapil, N. Chhabra, and S. Dhawan. 2011. Design and development of paclitaxel-loaded bovine serum albumin nanoparticles for brain targeting. Acta Pharm. 61:141-156.

Bloomfield, V. A. 2000. Static and dynamic light scattering from aggregating particles. Biopolymers 54:168-172.

Bramaud, C., P. Aimar, and G. Daufin. 1997. Whey protein fractionation: isoelectric precipitation of alpha-lactalbumin under gentle heat treatment. Biotechnol. Bioeng. 56:391-397.

Cardamone, M., and N. K. Puri. 1992. Spectrofluorimetric assessment of the surface hydrophobicity of proteins. Biochem. J. 282:589593.

Cawthern, K. M., M. Narayan, D. Chaudhuri, E. A. Permyakov, and E. J. Berliner. 1997. Interactions of $\alpha$-lactalbumin with fatty acids and spin label analogs. J. Biol. Chem. 272:30812-30816.

Charteris, W. P., P. M. Kelly, L. Morelli, and J. K. Collins. 1998. Development and application of an in vitro methodology to determine the transit tolerance of potentially probiotic Lactobacillus and Bifidobacterium species in the upper human gastrointestinal tract. J. Appl. Microbiol. 84:759-768.

Chen, L., G. E. Remondetto, and M. Subirade. 2006. Food proteinbased materials as nutraceutical delivery systems. Trends Food Sci. Technol. 17:272-283.

Coester, C. J., K. Langer, H. Van Briesen, and J. Kreuter. 2000. Gelatin nanoparticles by two-step desolvation-A new preparation method, surface modification and cell uptake. J. Microencapsul. 17:187-193.

Desai, M. P., V. Labhasetwar, G. L. Amidon, and R. J. Levy. 1996. Gastrointestinal uptake of biodegradable microparticles: Effect of particle size. Pharm. Res. 13:1838-1845.

Elias, R. J., S. S. Kellerby, and E. A. Decker. 2008. Antioxidant activity of proteins and peptides. Crit. Rev. Food Sci. Nutr. 48:430-441.

Ensign, L. M., R. Cone, and J. Hanes. 2012. Oral drug delivery with polymeric nanoparticles: The gastrointestinal mucus barriers. Adv. Drug Deliv. Rev. 64:557-570.

Farrell, H. M., R. Jimenez-Flores, G. T. Bleck, E. M. Brown, J. E. Butler, L. K. Creamer, C. L. Hicks, C. M. Hollar, K. F. Ng-KwaiHang, and H. E. Swaisgood. 2004. Nomenclature of the proteins of cows' milk - Sixth revision. J. Dairy Sci. 87:1641-1674.

Gaumet, M., A. Vargas, R. Gurny, and F. Delie. 2008. Nanoparticles for drug delivery: The need for precision in reporting particle size parameters. Eur. J. Pharm. Biopharm. 69:1-9.

Gunasekaran, S., S. Ko, and L. Xiao. 2007. Use of whey proteins for encapsulation and controlled delivery applications. J. Food Eng. 83:31-40.

Jahanshahi, M., and Z. Babaei. 2008. Protein nanoparticle: A unique system as drug delivery vehicles. Afr. J. Biotechnol. 7:4926-4934.

Jun, J. Y., H. H. Nguyen, S. Y. R. Paik, H. S. Chun, B. C. Kang, and S. Ko. 2011. Preparation of size-controlled bovine serum albumin (BSA) nanoparticles by a modified desolvation method. Food Chem. 127:1892-1898

Kamau, S. M., S. C. Cheison, W. Chen, X. M. Liu, and R. R. Lu. 2010. Alpha-lactalbumin: Its production technologies and bioactive peptides. Comp. Rev. Food Sci. Food Safety 9:197-212. 
Kreuter, J. 2007. Nanoparticles-A historical perspective. Int. J. Pharm. 331:1-10.

Langer, K., M. G. Anhorn, I. Steinhauser, S. Dreis, D. Celebi, N. Schrickel, S. Faust, and V. And Vogel. 2008. Human serum albumin (HSA) nanoparticles: Reproducibility of preparation process and kinetics of enzymatic degradation. Int. J. Pharm. 347:109117.

Langer, K., S. Balthasar, V. Vogel, N. Dinauer, H. von Briesen, and D. And Schubert. 2003. Optimization of the preparation process for human serum albumin (HSA) nanoparticles. Int. J. Pharm. 257:169-180.

Mehravar, R., M. Jahanshahi, G. D. Najafpour, and N. Saghatoleslami. 2011. Applying the Taguchi method for optimized fabrication of $\alpha$-lactalbumin nanoparticles as carrier in drug delivery and food science. Iranica J. Energy Environ. 2:87-91.

Mehravar, R., M. Jahanshahi, and N. Saghatoleslami. 2009. Production of biological nanoparticles from $\alpha$-lactalbumin for drug delivery and food science application. Afr. J. Biotechnol. 8:6822-6827.

Mohanraj, V. J., and Y. Chen. 2006. Nanoparticles-A review. Trop. J. Pharm. Res, 5:561-573.

Morrison, R. T., and R. N. Boyd. 1992. Organic Chemistry. 6th ed. Prentice Hall, Englewood Cliffs, NJ.

Müller-Buschbaum, P., R. Gebhardt, S. V. Roth, E. Metwalli, and W. Doster. 2007. Effect of calcium concentration on the structure of casein micelles in thin films. Biophys. J. 93:960-968.

Plapied, L., N. Duhem, N. des Rieux, and V. Préat. 2011. Fate of polymeric nanocarriers for oral drug delivery. Curr. Opin. Colloid. Sci. 16:228-237.

Re, R., N. Pellegrini, A. Proteggente, M. Yang, and C. Rice-Evans. 1999. Antioxidant activity applying an improved ABTS radical cation decolorization assay. Free Radic. Biol. Med. 26:1231-1237.

Rodiles-López, J. O., I. J. Arroyo-Maya, M. E. Jaramillo-Flores, G. F. Gutiérrez-López, A. Hernández-Arana, G. V. Barbosa-Cánovas, K. Niranjan, and H. Hernández-Sánchez. 2010. Effects of high hydrostatic pressure on the structure of bovine $\alpha$-lactalbumin. J. Dairy Sci. 93:1420-1428.

Rodiles-López, J. O., M. E. Jaramillo-Flores, G. F. Gutiérrez-López, A. Hernández-Arana, R. E. Fosado-Quiroz, G. V. Barbosa-Cáno- vas, and H. Hernández-Sánchez. 2008. Effect of high hydrostatic pressure on bovine $\alpha$-lactalbumin functional properties. J. Food Eng. 87:363-370

Salami, M., R. Yousefi, M. R. Ehsani, S. H. Razavi, J. M. Chobert, T. Haertlé, A. A. Saboury, M. S. Atri, A. Niasari-Naslaji, F. Ahmad, and A. A. Moosavi-Movahedi. 2009. Enzymatic digestion and antioxidant activity of the native and molten globule states of camel $\alpha$-lactalbumin: Possible significance for use in infant formula. Int Dairy J. 19:518-523.

Singh, H. D., G. Wang, H. Uludag, and L. D. And Unsworth. 2010 Poly-L-lysine-coated albumin nanoparticles: Stability, mechanism for increasing in vitro enzymatic resilience, and siRNA release characteristics. Acta Biomater. 6:4277-4284.

Smith, P. K., R. I. Krohn, G. T. Hermanson, A. K. Mallia, F. H. Gartner, M. D. Provenzano, E. K. Fujimoto, N. M. Goeke, B. J. Olson, and D. C. Klenk. 1985. Measurement of protein using bicinchoninic acid. Anal. Biochem. 150:76-85.

Snyder, L. R. 1978. Classification of the solvent properties of common liquids. J. Chromatogr. Sci. 16:223-234.

Vogel, V., K. Langer, S. Balthasar, P. Schuck, W. Mächtle, W. Haase, J. A. van den Broek, C. Tziatzios, and D. Schubert. 2002. Characterization of serum albumin nanoparticles by sedimentation velocity analysis and electron microscopy. Prog. Colloid Polym. Sci. 119:31-36

Wade, T., J. K. Beattie, W. N. Rowlands, and M. A. Augustin. 1996 Electroacoustic determination of size and zeta potential of casein micelles in skim milk. J. Dairy Res. 63:387-404.

Weber, C., C. Coester, J. Kreuter, and K. Langer. 2000. Desolvation process and surface characterisation of protein nanoparticles. Int. J. Pharm. 194:91-102.

Wehbi, Z., M. D. Pérez, L. Sánchez, C. Pocoví, C. Barbana, and M. Calvo. 2005. Effect of heat treatment on denaturation of bovine $\alpha$-lactalbumin: Determination of kinetics and thermodynamic parameters. J. Agric. Food Chem. 53:9730-9736.

Wei, X., Y. K. Lee, K. M. Huh, S. Kim, and K. Park. 2009. Safety and efficacy of nano/micro materials. Pages 63-88 in Safety of Nanoparticles: From Manufacturing to Medical Applications. T. J. Webster, ed. Springer, New York, NY. 